OPEN ACCESS

Edited by:

Luigi Vimercati,

University of Bari Aldo Moro, Italy

Reviewed by:

Yuke Tien Fong,

Singapore General

Hospital, Singapore

Giovanni Maria Ferri

University of Bari Medical School, Italy

Tsegaye Adane,

University of Gondar, Ethiopia

*Correspondence:

Awoke Keleb

kalebawoke@gmail.com

Specialty section:

This article was submitted to Occupational Health and Safety,

a section of the journa

Frontiers in Public Health

Received: 24 September 2021 Accepted: 02 November 2021 Published: 02 December 2021

Citation:

Keleb A, Ademas A, Lingerew M,

Sisay T, Berihun $G$ and Adane $M$

(2021) Prevention Practice of COVID-19 Using Personal Protective Equipment and Hand Hygiene Among Healthcare Workers in Public Hospitals of South Wollo Zone, Ethiopia. Front. Public Health 9:782705.

doi: 10.3389/fpubh.2021.782705

\section{Prevention Practice of COVID-19 Using Personal Protective Equipment and Hand Hygiene Among Healthcare Workers in Public Hospitals of South Wollo Zone, Ethiopia}

\author{
Awoke Keleb*, Ayechew Ademas, Mistir Lingerew, Tadesse Sisay, Gete Berihun and \\ Metadel Adane \\ Department of Environmental Health, College of Medicine and Health Science, Wollo University, Dessie, Ethiopia
}

Objective: The use of personal protective equipment and hand hygiene are often the most recommended line of defense against coronavirus disease-19 (COVID-19). The purpose of this study is to determine the magnitude of compliance and associated factors of personal protective equipment (PPE) utilization and hand hygiene practice among healthcare workers in public hospitals of South Wollo Zone, Northeastern Ethiopia.

Methods: A hospital-based cross-sectional study was conducted among 489 healthcare workers in public hospitals of South Wollo Zone, Northeastern Ethiopia from June 15 to July 30, 2021. Proportional sample size allocation to each selected hospital followed by simple random sampling techniques were used to select the study participants using human resource records from each hospital. A pre-tested and structured self-administered questionnaire with WHO's standardized hand hygiene and PPE utilization observational checklist were used to collect data. Bivariate and multivariable analyses with $95 \% \mathrm{Cl}$ and $p$-value $<0.05$ were employed to identify the associated factors of personal protective equipment utilization.

Results: About 32 and $22.3 \%$ of healthcare workers were compliant with personal protective equipment utilization and hand hygiene practice, respectively. Feedback for safety $(\mathrm{AOR}=2.05 ; 95 \% \mathrm{Cl}: 1.26-3.35)$, training on COVID-19 prevention (AOR $=3.43 ; 95 \% \mathrm{Cl}: 2.01-5.86)$, and perception to infection risk ( $\mathrm{AOR}=1.98 ; 95 \%$ Cl: 1.18-3.33) were significant factors of good compliance with personal protective equipment utilization.

Conclusion: The magnitude of good compliance with personal protective equipment utilization and hand hygiene was low. Interventions to promote personal protective equipment utilization and hand hygiene should focus on feedback for safety, training on COVID-19 prevention, and perception of infection risk.

Keywords: COVID-19, compliance, hand hygiene, health care, personal protective equipment 


\section{INTRODUCTION}

The coronavirus (COVID-19) pandemic has overwhelmingly changed the world and, consequently, is changing the conditions of healthcare workers (HCWs) (1). This pandemic is creating profound challenges for healthcare workers and healthcare systems in the world, as the disease is spreading at an alarming rate, surpassing hospital capacities and exposing healthcare workers to a high risk of exposure (2). The outbreak of severe acute respiratory syndrome coronavirus (SARS-CoV-2) was first reported in Wuhan, Hubei province, China, in late December 2019 and has rapidly spread to other countries (1).

SARS-CoV-2 is especially transmitted through droplets and touch (3) especially during airway maneuvers in an infected patient, like during tracheal intubation $(4,5)$. The majority of people infected with the coronavirus are associated with occupational exposure. COVID-19 could also be the primary new industrial disease during this decade (6). It is believed that the primary occupational groups in danger are persons working in seafood and wet animal markets in Wuhan (3).

As of July 2021, over 206 million confirmed cases of COVID-19, the disease caused by SAR-CoV-2, and close to 4.4 million confirmed deaths were reported by the World Health Organization (WHO) (4). The cumulative number of cases within the African continent is over 6.5 million $(6,587,734)$ confirmed COVID-19 cases which accounts for $3.4 \%$ of the total cases reported globally, and 167,183 deaths with a $2.5 \%$ fatality rate $(4,5)$. A global systematic review indicated that a total of 152,888 infections and 1,413 deaths were reported among healthcare workers worldwide. Infections were mainly in women and nurses but deaths were mainly in men and doctors (7).

The people most in danger of infection are those that are in close contact with a COVID-19 patient or who look after COVID-19 patients. Subsequently, healthcare workers are a subsequent high-risk group to accumulate this infection (8). According to OSHA, high-risk workers include those involved in healthcare, death care, laboratories, airline operations, solid waste, and wastewater management and visit areas where the virus is spreading (9).

Since, HCWs are putting themselves at high risk of COVID19, measures to stop SARS-CoV-2 transmission in healthcare staff are an instantaneous priority $(5,10)$; therefore, HCWs are required to protect themselves and stop transmission within the healthcare setting (3) since the health and well-being of our healthcare workers determine our nation's health, security, and economic prosperity.

Of concern, doctors are significantly suffering from COVID19 in Africa, with 14,148 HCWs being infected in many counties since the start of the outbreak. Overall, South Africa has been the foremost affected, with 4,842 (34\%) infected, followed by Algeria $(2,300)$, Ghana (2,065), Nigeria (987), Cameroon (593), Senegal

Abbreviations: 2019-ncov, 2019-novel coronavirus; AOR, adjusted odds ratio; CI, confidence interval; COR, crude odds ratio; COVID-19, coronavirus disease-2019; CSA, Central Statistical Agency; HCWs, healthcare workers; PPE, personal protective equipment; SARS-CoV-2, severe acute respiratory syndromecoronavirus-2; SPSS, Statistical Package for Social Science; WHO, World Health Organization.
(271), Guinea-Bissau (268), Malawi (264), Guinea (244), Côte d'Ivoire (187), Liberia (184), Niger (184), Sierra Leone (168), and Ethiopia $(87)(2,11)$.

WHO and other national and international public health authorities recommend proper personal protective equipment (PPE) utilization and hand hygiene compliance $(3,5)$. As a result, any potential transmission can be prevented, thereby HCWs are often protected. Although the foremost effective interventions to protect HCWs are to physically separate HCWs from infectious patients and body fluids, mortality rates of COVID-19-infected patients are often decreased with more aggressive care that needs close contact with these patients $(12,13)$.

During this setting, adhering to PPE utilization and hand hygiene practice are the last physical barrier between a healthcare provider and infectious body fluids $(2,6)$. However, there is a big discrepancy concerning access and utilization of PPE and hand hygiene protocols which are not always followed in many medical institutions during COVID-19 patient management.

The speed with which COVID-19 is spreading across the world involves an assessment of the reality of healthcare workers' PPE utilization and hand hygiene during the COVID19 pandemic $(1,3,14)$. Even though hand hygiene is the most critical intervention for protecting HCWs from infections including COVID-19, the compliance rate for hand hygiene has not drastically improved (15). This study aims to determine compliance of personal protective equipment utilization and hand hygiene practice and associated factors among healthcare workers toward the COVID-19 pandemic in hospital settings.

\section{METHODS}

\section{Study Setting}

South Wollo Zone is one among 10 zones within the Amhara Region of Ethiopia (Figure 1).

Based on the 2007 Census conducted by the Central Statistical Agency of Ethiopia (CSA), this zone features a complete population of $2,518,862$, an increase of $18.60 \%$ over the 1994 census, of whom 1,248,698 are men and 1,270,164 are women in an area of 17,067.45 square kilometers. South Wollo has a population density of 147.58 . While $301,638(11.98 \%)$ are urban inhabitants, a further 2,217,224 (88.02\%) inhabitants were reported to be rural. A total of 598,447 households were counted in this zone, which can be calculated in a mean of 4.21 persons to a household, and 574,378 housing units. There are seven public hospitals in the South Wollo Zone with a total of 1,051 healthcare workers to serve the catchment population of the South Wollo Zone and the nearby zones especially for the Afar region.

\section{Study Design and Period}

A hospital-based cross-sectional study was conducted to assess the magnitude of compliance with personal protective equipment utilization and hand hygiene and its associated factors among healthcare workers in public hospitals of South Wollo Zone, Northeastern Ethiopia from June 15 to July 30, 2021. 


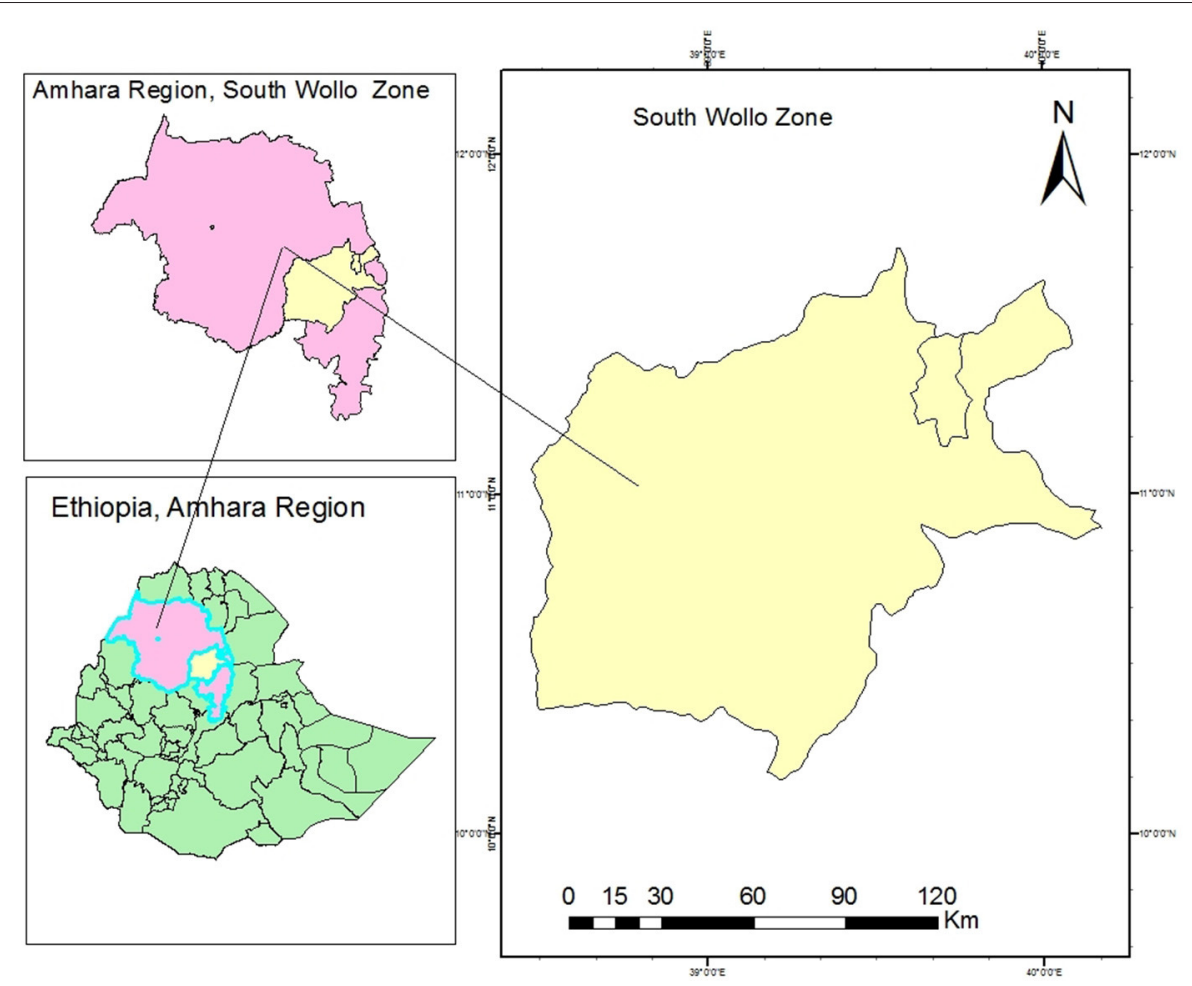

FIGURE 1 | Map of the study area.

\section{Source Population and Inclusion Criteria}

The source population of this study was all healthcare workers working in South Wollo Zone hospitals while the study population was all selected healthcare workers in South Wollo Zone hospitals. From the study population, all permanent healthcare workers employed in the hospitals were included in the study.

\section{Sample Size Determination and Sampling Procedure}

The sample size was determined using the single population proportion formula with the following assumptions: Magnitude of compliance with standard precaution practice $(p=12 \%)$ was taken from a study conducted in Gondar University Comprehensive Specialized Hospital, Northwest Ethiopia (16).

$n=\frac{\left(Z_{a / 2}\right)^{2} * p(1-p)}{d^{2}}$ where $\mathbf{n}$ is the optimum sample size required, $\mathbf{P}$ is an estimate of the magnitude of compliance with standard precaution, $\mathbf{Z}$ is the standard normal variable at a $(1-\alpha)$ $\%$ confidence level, $\alpha$ is mostly 0.05 , i.e., with $95 \%$ CI $(z=1.96)$, and $\mathbf{d}$ is the margin of error to be tolerated (\%).

The determination of the margin of error is based on the optimum sample size and availability of resources considering one percent (1\%) giving the largest sample size and 5\% giving the smallest sample size. For this study, a margin of 3\% was used which was based on the proportion of $12 \%$ taken from a similar study mentioned above, which gave an adequate sample size.

$$
n=\frac{(1.96)^{2} * 0.12(1-0.12)}{(0.03)^{2}}=451
$$

After adding a $10 \%$ non-response rate the final sample size was $\boldsymbol{n}=\mathbf{4 9 6}$.

There are seven public hospitals in the South Wollo Zone from which three hospitals were selected randomly. All 496 estimated participants were proportionally allocated to each hospital based upon their respective numbers of healthcare workers. The sample size from each hospital was proportionally allocated based on the types of profession (strata) and numbers of their healthcare workers. The study participants were selected using a simple random sampling method within their strata using human resource records from each hospital.

\section{Dependent and Independent Variables}

\section{Dependent Variables}

- Personal protective equipment utilization (good compliance/poor compliance).

- Hand hygiene practice (good compliance/poor compliance).

\section{Independent Variables}

Socio-Demographic Factors

Age of respondent, sex, marital status, type of profession, educational status and work experience, and respondent working unit. 


\section{Institutional Factors}

Availability of PPE, presence of COVID guidelines, and feedback for safety.

\section{Behavioral Factors}

Infection prevention training on COVID-19, perception of infection risk, drinking alcohol, chewing khat, and hand hygiene practice.

\section{Operational Definition}

\section{PPE Utilization and Hand Hygiene Measurement}

Compliance was measured using data from direct observations by trained BSc nurses.

\section{Compliance of Personal Protective Equipment Utilization}

Good compliance with PPE utilization was considered when the HCW scored more than or equal to the mean score, and a score less than the mean score was taken as "poor compliance" from the observational checklist (17-19).

\section{Hand Hygiene Compliance}

Good hand hygiene compliance was considered when the $\mathrm{HCW}$ scored more than or equal to the mean score from the observational checklist $(20,21)$.

\section{Data Collection Tools and Quality Assurance}

The data were collected using WHO's standardized hand hygiene and PPE utilization observational checklist (22-24). The observation was focused on six moments of PPE use: wearing a face mask, eye goggle, apron, glove, and gown, while observation for hand hygiene was focused on six domains: washing hands before touching a patient, before clean or aseptic procedures, after body fluid exposure, after touching a patient, immediately after removal of gloves, and between patient contact. Before actual data collection, six observers (BSc nurses) and three supervisors (public health experts) were trained for two days in accordance with WHO hand hygiene and PPE utilization techniques focused on each item on the observational checklist plus additional time for observing the practice and considering ethical issues. After training, a pre-test was conducted on 25 healthcare workers in nearby Woldeya Hospital, North Wollo Zone, Ethiopia.

During observation, the data collectors directly observed the study participants while the HCWs conducted clinical examinations on patients. The observation was made on nine units in the selected hospitals: emergency room, pediatrics ward, delivery/gynecology ward, medical ward, surgical ward, operation theater unit, laboratory, radiology unit, recovery, outpatient department (OPD), and a physiotherapy room. Along with standing concern with clinical observation is the Hawthorne effect, in which study subjects' awareness of being observed causes them to alter their behavior. To minimize such bias, data collectors were coached to observe discretely in which the HCWs were unaware of the research activities. Some days after the completion of observation, a self-administered pretested structure questionnaire was distributed to the same HCWs to collect other required information such as socio-demographic, institutional, and behavioral factors. Three public health experts supervised the data collection process including observation and completeness of questionnaires by giving daily feedback to data collectors before data entry.

\section{Statistical Analysis}

Data were entered using EpiData version 3.1 and exported to Statistical Package of Social Science (SPSS) version 25.0 for data cleaning and analysis. Once the data were entered, basic quality assurance measures including data cleaning using browsing of data tables after sorting, frequency distributions, and cross-tabulations and summary statistics using sorting were performed. Descriptive statistics were used for sociodemographic characteristics and mean \pm SD (standard deviations) for continuous variables. Continuous variables were categorized using information from the literature, and categorical variables were re-categorized accordingly.

Bivariate (crude odds ratio [COR]) and multivariable (adjusted odds ratio $[\mathrm{AOR}]$ ) values were calculated using logistic regression analysis with a $95 \%$ confidence interval [CI]. From the bivariate analysis, variables with $p<0.25$ were considered as candidate variables for multivariable analysis and AOR was determined after adjusting for the availability of PPE, feedback for safety, training on COVID19 prevention, perception to infection risk, drinking alcohol, and chewing khat using the backward stepwise method. From the multivariable logistic regression analysis, variables with a significance level of $p<0.05$ were taken as statistically significant and independently associated with compliance with personal protective equipment utilization. The presence of multicollinearity among independent variables was checked using standard error at the cutoff value of 2 . Model fitness was checked using the Hosmer-Lemeshow test which had a $p$-value $>0.05$.

\section{RESULTS}

\section{Socio-Demographic Characteristics of the Respondents}

A total of 489 healthcare workers were observed and completed the survey with a response rate of $98.6 \%$. More than half of the participants were women which accounts for 276 (56.4\%), nearly half 238 (48.7\%) of the HCWs were married, and the majority of the participants 292 (59.7\%) were nurses. About two-thirds 343 (70.2\%) of the respondents had Bachelor degrees and 367 (75.1\%) of the respondents had $>10$ years of work experience (Table 1).

\section{Institutional and Behavioral Factors}

More than three-quarters 381 (77.9\%) of the healthcare workers had personal protective equipment in their working department and nearly three-quarters 361 (73.8\%) reported having COVID19 guidelines as a working protocol for COVID-19 management but less frequent feedback for safety 390 (79.8\%) was given by the infection prevention officers. Even though, nearly two-thirds $300(61.3 \%)$ of the HCWs had a perception of infection risk, only half $256(52.4 \%)$ of healthcare workers had taken training on COVID-19 prevention and control (Table 2). 
TABLE 1 | Socio-demographic characteristics of healthcare workers in public hospitals of South Wollo Zone, Northeastern Ethiopia, 2021.

\begin{tabular}{|c|c|c|c|}
\hline Variables & Category & Frequency (n) & Percentage (\%) \\
\hline \multirow[t]{2}{*}{ Sex } & Male & 213 & 43.6 \\
\hline & Female & 276 & 56.4 \\
\hline \multirow[t]{3}{*}{ Age of respondent } & $19-30$ & 156 & 41.9 \\
\hline & $31-40$ & 172 & 46.2 \\
\hline & 41 and above & 44 & 11.8 \\
\hline \multirow[t]{2}{*}{ Marital status } & Currently unmarried & 251 & 51.3 \\
\hline & Currently married & 238 & 48.7 \\
\hline \multirow[t]{11}{*}{ Respondent working unit } & Emergency room & 33 & 6.7 \\
\hline & Pediatrics ward & 45 & 9.2 \\
\hline & Delivery or gyn ward & 81 & 16.6 \\
\hline & Medical ward & 68 & 13.9 \\
\hline & Surgical ward & 22 & 4.5 \\
\hline & Operation theater unit & 42 & 8.6 \\
\hline & Laboratory & 63 & 12.9 \\
\hline & Radiology unit & 32 & 6.5 \\
\hline & Recovery & 33 & 6.7 \\
\hline & OPD & 53 & 10.8 \\
\hline & Physiotherapy room & 17 & 3.5 \\
\hline \multirow[t]{5}{*}{ Educational status } & Certificate & 70 & 14.3 \\
\hline & Diploma & 76 & 15.5 \\
\hline & $\mathrm{BSc}$ & 199 & 40.7 \\
\hline & Medical doctor & 107 & 21.9 \\
\hline & MSc/specialist & 37 & 7.6 \\
\hline \multirow[t]{3}{*}{ Work experience in years } & $>10$ years & 367 & 75.1 \\
\hline & 5-10 years & 95 & 19.4 \\
\hline & $<5$ years & 27 & 5.5 \\
\hline \multirow[t]{4}{*}{ Types of profession } & Nurses & 292 & 59.7 \\
\hline & Medical doctor & 122 & 24.9 \\
\hline & Laboratory & 39 & 8.0 \\
\hline & Other allied HCWs & 36 & 7.4 \\
\hline
\end{tabular}

\section{Personal Protective Equipment Utilization}

In the routine care of patients in the healthcare setting, most HCWs reported that they always wear FFP2/N95 facemasks (245, $50.1 \%)$, gowns and gloves were used for routine care among 305 (62.4\%) and 319 (65.2\%) HCWs, respectively while 156 (31.9\%) HCWs used eye goggles and aprons independently. According to this study, the overall number of HCWs who were compliant with personal protective equipment utilization was found to be 156 (31.9\%) (95\% CI: 27.9-36.6) (Table 3). Furthermore, the least compliant healthcare workers were laboratory professionals followed by nurses and doctors (Table 4 ).

\section{Hand Hygiene Measurement Domains}

The potential range of cumulative hand hygiene domain score was $0-6$, and we assessed a mean score of $3.56 \pm 1.31$. According to the observational result, only one-third $153(31.3 \%)$, more than half 269 (55.0\%), and much more than three-quarters $427(87.3 \%)$ of them practiced hand washing before touching a patient, before clean or aseptic procedures, and after body fluid
TABLE 2 | Institutional and behavioral factors of healthcare workers in public hospitals of South Wollo Zone, Northeastern Ethiopia, 2021.

\begin{tabular}{llcc}
\hline Variable & Category & Frequency (n) & Percentage (\%) \\
\hline Availability of PPE & No & 108 & 22.1 \\
& Yes & 381 & 77.9 \\
Presence of COVID guidelines & No & 128 & 26.2 \\
& Yes & 361 & 73.8 \\
Feedback for safety & Less frequent & 390 & 79.8 \\
\multirow{2}{*}{ Training on COVID-19 } & More frequent & 99 & 20.2 \\
\multirow{4}{*}{ Perception to infection risk } & No & 233 & 47.6 \\
& Yes & 256 & 52.4 \\
Drinking alcohol & No & 189 & 38.7 \\
\multirow{2}{*}{ Chewing khat } & No & 300 & 61.3 \\
& Yes & 391 & 80.0 \\
& No & 98 & 20.0 \\
& Yes & 423 & 86.5 \\
\hline
\end{tabular}

TABLE 3 | Compliance of PPE utilization measurement indications among healthcare workers in public hospitals of South Wollo Zone, Northeastern Ethiopia, 2021.

\begin{tabular}{lcc}
\hline PPE use indications & No & Yes \\
\hline Wearing facemasks & $244(49.9 \%)$ & $245(50.1 \%)$ \\
Wearing eye goggles & $333(68.1 \%)$ & $156(31.9 \%)$ \\
Wearing aprons & $331(67.7 \%)$ & $158(32.3 \%)$ \\
Wearing gloves & $170(34.8 \%)$ & $319(65.2 \%)$ \\
Wearing gowns & $184(37.6 \%)$ & $305(62.4 \%)$ \\
Overall PPE utilization compliance & Poor compliance & $333(68.1 \%)$ \\
& Good compliance & $156(31.9 \%)$ \\
\hline
\end{tabular}

TABLE 4 | Proportion of HCW compliance with PPE utilization by professionals in public hospitals of South Wollo Zone, Northeastern Ethiopia, 2021.

\begin{tabular}{lccccc}
\hline \multirow{2}{*}{ Professions } & \multicolumn{4}{c}{ PPE utilization } \\
\cline { 2 - 3 } & \multicolumn{2}{c}{ Good compliance } & & \multicolumn{2}{c}{ Poor compliance } \\
\cline { 2 - 3 } \cline { 5 - 6 } & Frequency & Percentage & & Frequency & Percentage \\
\hline Nurses & 107 & $21.88 \%$ & & 185 & $37.83 \%$ \\
Doctors & 28 & $5.73 \%$ & & 30 & $6.13 \%$ \\
Laboratory & 9 & $1.84 \%$ & & 94 & $19.22 \%$ \\
Other allied HCWs & 12 & $2.45 \%$ & & 24 & $4.92 \%$ \\
Total & 156 & $31.9 \%$ & & 333 & $68.1 \%$ \\
\hline
\end{tabular}

exposure, respectively. Moreover, 157 (32.1\%), 429 (87.7\%), and $176(36.0 \%)$ HCWs practiced hand washing after touching a patient, immediately after removal of gloves, and between patient contact, respectively. The overall number of HCWs who had good compliance with hand hygiene was found to be $294(22.3 \%)$ (95\% CI: 18.8-26.0) (Table 5). 
TABLE 5 | Hand hygiene domains among healthcare workers toward COVID-19 in public hospitals of South Wollo Zone, Northeastern Ethiopia, 2021.

\begin{tabular}{|c|c|c|}
\hline Domains & No & Yes \\
\hline $\begin{array}{l}\text { Washing hands before touching a } \\
\text { patient }\end{array}$ & $336(68.7 \%)$ & $153(31.3 \%)$ \\
\hline $\begin{array}{l}\text { Washing hands before clean or } \\
\text { aseptic procedures }\end{array}$ & $220(45.0 \%)$ & 269 (55.0\%) \\
\hline $\begin{array}{l}\text { Washing hands after body fluid } \\
\text { exposure }\end{array}$ & $62(10.2 \%)$ & $427(87.3 \%)$ \\
\hline $\begin{array}{l}\text { Washing hands after touching a } \\
\text { patient }\end{array}$ & 332 (67.8\%) & $157(32.1 \%)$ \\
\hline $\begin{array}{l}\text { Washing hands immediately after } \\
\text { removal of gloves }\end{array}$ & $60(12.3 \%)$ & $429(87.7 \%)$ \\
\hline $\begin{array}{l}\text { Washing hands between patient } \\
\text { contact }\end{array}$ & $313(64.0 \%)$ & $176(36.0 \%)$ \\
\hline \multirow[t]{2}{*}{ Overall hand hygiene compliance } & Poor compliance & $380(77.7 \%)$ \\
\hline & Good compliance & 294 (22.3\%) \\
\hline
\end{tabular}

\section{Factors Associated With Personal Protective Equipment Utilization}

The adjusted logistic regression analysis result indicated that feedback for safety $(\mathrm{AOR}=2.05 ; 95 \% \mathrm{CI}: 1.26-3.35)$, training on COVID-19 prevention (AOR $=3.43$; 95\% CI: $2.01-5.86$ ), and perception to infection risk (AOR $=1.98$; 95\% CI: $1.18-$ 3.33) were significantly associated with compliance of personal protective equipment utilization (Table 6).

\section{DISCUSSION}

The present study assessed compliance of personal protective equipment (PPE) utilization and hand hygiene practice among 489 healthcare workers toward COVID-19 in public hospital settings in which findings of the present study are very essential to prevent the spread of COVID-19 $(25,26)$. Because HCWs are the frontline to prevent and control COVID-19, they are at high risk of contracting an infection and can transmit the virus to patients, families, and the community easily $(5,27)$.

This study result revealed that overall adherence to PPE utilization among healthcare workers was low. The observed utilization of PPE in this study was more frequent than the study findings from Nigeria (28), Gondar, Ethiopia (16), and India (29) in which HCWs who always complied with appropriate use of PPEs ranged from 4.3 to $18.1 \%$. However, it was lower than systematic reviews studies conducted in industrialized countries on compliance with hand hygiene in hospital care: in intensive care units (30-40\%), in other departments (50-60\%), among physicians (32\%), and nurses (48\%) (30) and more than $50 \%$ in the emergency department (31).

The main reason for low adherence to PPE utilization in this study may due to lack of training about the use and function of PPE utilization for COVID-19 and other disease prevention methods (only half of HCWs reported that they received infection prevention training since the COVID-19 outbreak emerged). Training on infection prevention especially for COVID-19 can enhance compliance of PPE utilization and hand hygiene practice (32) and can reduce the perception of risk (33). Besides, insufficient time, carelessness, discomfort, forgetfulness, lack of habit, and perception of low risk of infection might be other factors for low compliance in PPE utilization.

Hand hygiene is the most essential protective measure to prevent infection, especially SARS-CoV-2. However, the overall compliance of hand hygiene practices among healthcare workers was low. A worldwide systematic review indicated that the overall compliance rate of hand hygiene in hospital care was $40 \%$ (30). In this study, lower compliance of hand hygiene practice was reported among doctors (18.9\%) than nurses which may be influenced by lack of positive role models and perception of intensified dryness and soreness of hands. It might also be due to the inconvenient placement of the hand rub or sink, no hand rub in the dispenser, or no soap at the sink, being distracted by medical emergencies, low perception of hand hygiene importance to prevent infections, and low safety culture with no feedback for safety.

This study finding also indicated that lack of training on COVID-19 prevention can decrease compliance of PPE utilization among HCWs by more than three-fold $(\mathrm{AOR}=$ 3.43). This means that HCWs who had training on COVID19 prevention were 3.43 times more likely to use the personal protective equipment compared to HCWs who had no previous training on COVID-19 prevention. It is similar to those earlier results found in studies done in Amhara regional state (34), Ethiopia (35), Egypt (36), Tanzania (20), and Italy (33).

Healthcare workers who received frequent feedback on safety practices by institutional management had more than twofold $(\mathrm{AOR}=2.05)$ higher compliance with PPE utilization. Compliance can be increased through personal or management supervision, instruction, and audit performance by providing feedback for safety (37). This finding is also supported by evidence that HCWs with a good perception of infection risk were nearly two times $(\mathrm{AOR}=1.98)$ more likely to comply with PPE utilization in line with studies done in Addis Ababa, Ethiopia (38), and Italy (33). This indicated that increased perception of infection risk toward COVID-19 might empower HCWs to adhere to PPE utilization against the disease.

\section{CONCLUSIONS}

Healthcare workers' compliance on personal protective equipment utilization and hand hygiene practice was inadequate in the public hospitals of South Wollo Zone. The multivariable logistic regression analysis result indicated that feedback for safety, training on COVID-19 prevention, and perception to infection risk were the main predictor variables for compliance of personal protective equipment utilization.

These study results indicate the imperative need for decisionmakers to address low compliance on personal protective equipment utilization and hand hygiene practice among HCWs in hospital settings. These findings should inform strategies designed to increase training on COVID-19 prevention and 
TABLE 6 | Factors associated with personal protective equipment utilization among healthcare workers toward COVID-19 in public hospitals of South Wollo Zone, Northeastern Ethiopia $(n=489)$

\begin{tabular}{|c|c|c|c|c|c|}
\hline \multirow[t]{2}{*}{ Variable } & \multirow[t]{2}{*}{ Category } & \multicolumn{2}{|c|}{ PPE Utilization } & \multirow[t]{2}{*}{ COR $(95 \% \mathrm{Cl})$} & \multirow[t]{2}{*}{ AOR $(95 \% \mathrm{Cl})$} \\
\hline & & Poor compliance & Good compliance & & \\
\hline \multirow[t]{2}{*}{ Availability of PPE } & No & 70 & 38 & $1.22(0.79-1.87)$ & $1.63(0.93-2.85)$ \\
\hline & Yes & 263 & 118 & 1 & 1 \\
\hline \multirow[t]{2}{*}{ Feedback for safety } & No & 281 & 109 & $1.42(0.84-2.43)$ & $2.05(1.26-3.35)$ * \\
\hline & Yes & 52 & 47 & 1 & 1 \\
\hline \multirow[t]{2}{*}{ Training on COVID-19 } & No & 120 & 113 & 4.66 (3.08-7.07) & $3.43(2.01-5.86)^{\star}$ \\
\hline & Yes & 213 & 43 & 1 & 1 \\
\hline \multirow[t]{2}{*}{ Perception to infection risk } & No & 96 & 93 & $1.42(0.95-2.13)$ & $1.98(1.18-3.33)^{*}$ \\
\hline & Yes & 237 & 63 & 1 & 1 \\
\hline \multirow[t]{2}{*}{ Drinking alcohol } & No & 275 & 116 & 1.64 (1.04-2.58) & $0.99(0.44-2.07)$ \\
\hline & Yes & 58 & 40 & 1 & 1 \\
\hline \multirow[t]{2}{*}{ Chewing khat } & No & 297 & 126 & 1.96 (1.16-3.33) & $1.07(0.44-2.60)$ \\
\hline & Yes & 36 & 30 & 1 & 1 \\
\hline
\end{tabular}

This analysis was adjusted for availability of PPE, feedback for safety, training on COVID-19 prevention, perception to infection risk, drinking alcohol, and chewing chat. *Indicates variables significantly associated with PPE utilization at 95\% Cl.

management support for safety to change the behavioral determinants of compliance with the relevant practices. We strongly urge national governments, the private sector, and the general public to pay concerted attention to healthcare worker safety.

\section{DATA AVAILABILITY STATEMENT}

The raw data supporting the conclusions of this article will be made available by the authors, without undue reservation.

\section{ETHICS STATEMENT}

The study was conducted in accordance with the Helsinki declaration. The ethical approval letter was obtained from the Institutional Ethical Review Committee of the College of Medicine and Health Sciences of Wollo University with the issue number CMHS/368/13/21. Furthermore, before data collection, written consent was obtained from each healthcare worker. Before data collection, the purpose of the study was explained to all participants and they were assured that their information would not be used for purposes other than scientific research. Participants were informed that participation would be voluntary and that they could withdraw at any

\section{REFERENCES}

1. WHO. Maintaining Essential Health Services: Operational Guidance for the COVID-19 Context. Vol. 1, Interim guidance. Washington, DC: WHO (2020).

2. WHO. COVID-19 Situation Update for the WHO African Region. Washington, DC: WHO (2020).

3. Ramanathan K, Antognini D, Combes A, Paden M, Zakhary B, Ogino $\mathrm{M}$, et al. Transmission of SARS and MERS coronaviruses and influenza virus in healthcare settings: the possible role of dry surface contamination. J Hosp Infect. (2020) 92:235-50. doi: 10.1016/j.jhin.2015. 08.027 time for whatever reason. Confidentiality was maintained by avoiding possible identifiers such as the names of the study participants. Only identification numbers were used as a reference.

\section{AUTHOR CONTRIBUTIONS}

$\mathrm{AK}, \mathrm{AA}$, and MA contributed to the conception and design of the study. AK and AA conducted the investigation. AK, AA, TS, ML, and MA performed data management and analysis. AK, AA, GB, and MA wrote and edited the manuscript. All authors contributed to the article and approved the submitted version.

\section{FUNDING}

This work was supported by Wollo University (Grant No.: WU/20920/13).

\section{ACKNOWLEDGMENTS}

The authors express their heartfelt gratitude to human resource managers who gave valuable information for this study. They are also grateful for data collectors, supervisors, and hospital administrators.

4. WHO. COVID-19 Weekly Epidemiological Update. Washington, DC: WHO (2021).

5. WHO. Infection Prevention and Control During Health Care When Coronavirus Disease (COVID-19) is Suspected or Confirmed. Washington, DC: WHO (2021).

6. Koh D. Occupational risks for COVID-19 infection. Occup Med (Chic Ill). (2020) 70:3-5. doi: 10.1093/occmed/kqaa036

7. Bandyopadhyay S, Baticulon RE, Kadhum M, Alser M, Ojuka DK, Badereddin Y, et al. Infection and mortality of healthcare workers worldwide from COVID-19 : a systematic review. BMJ Glob Heal. (2020) 5:111. doi: 10.1136/bmjgh-2020-003097 
8. Nguyen LH, Drew DA, Joshi AD, Guo CG, Ma W, Mehta RS, et al. Risk of COVID-19 among frontline healthcare workers and the general community: a prospective cohort study. Lancet Public Health. (2020) 5:e47583. doi: 10.1101/2020.04.29.20084111

9. OSHA. Guidance on Preparing Workplaces for COVID-19. New York, NY: Department of Labor (2020). p. 1-35.

10. Abbas M, Robalo Nunes T, Martischang R, Zingg W, Iten A, Pittet D, et al. Nosocomial transmission and outbreaks of coronavirus disease 2019: the need to protect both patients and healthcare workers. Antimicrob Resist Infect Control. (2021) 10:1-13. doi: 10.1186/s13756-020-00875-7

11. WHO. COVID-19 Related Mortality and Morbidity Among Healthcare Providers. Washigton, DC: WHO (2021).

12. WHO. Infection Prevention and Control During Health Care When COVID-19 is Suspected. Washigton, DC: WHO (2020).

13. Delgado D, Quintana FW, Perez G, Liprandi AS. Personal Safety during the COVID-19 pandemic : realities and perspectives of healthcare workers in Latin America ${ }^{\dagger}$. Int J Environ Res Public Health. (2020) 17:18. doi: 10.3390/ijerph17082798

14. Houghton C, Meskell P, Delaney H, Smalle M, Glenton C, Booth A, et al. infectious diseases : a rapid qualitative evidence synthesis (Review). Cochrane Libr Syst Rev. (2020) 8:1-71. doi: 10.1002/14651858.CD013582

15. Nicholas SC. Handwashing in healthcare today: why haven't we gotten better? Clin J Nurs Care Pract. (2019) 3:014-6. doi: 10.29328/journal.cjncp.1001011

16. Haile TG, Engeda EH, Abdo AA. Compliance with standard precautions and associated factors among healthcare workers in Gondar University Comprehensive Specialized Hospital, Northwest Ethiopia. J Environ Public Health. (2017) 2017:2050635. doi: 10.1155/2017/2050635

17. Neuwirth MM, Mattner F, Otchwemah R. Adherence to personal protective equipment use among healthcare workers caring for confirmed COVID 19 and alleged non - COVID - 19 patients. Antimicrob Resist Infect Control [Internet]. (2020) 9:1-5. doi: 10.1186/s13756-020-00864-w

18. Zenbaba D, Sahiledengle B, Bogale D. Practices of healthcare workers regarding infection prevention in Bale Zone Hospitals, Southeast Ethiopia. Adv Public Heal. (2020) 2020:1-7. doi: 10.1155/2020/4198081

19. Deress W, Worku A, Abebe A, Gizaw M, Amogne W. Availability and use of personal protective equipment and satisfaction of healthcare professionals during COVID-19 pandemic in Addis Ababa, Ethiopia. Arch Public Heal. (2021) 79:1-14. doi: 10.1186/s13690-021-00668-3

20. Powell-jackson T, King JJC, Makungu C, Spieker N, Woodd S, Risha P, et al. Infection prevention and control compliance in Tanzanian outpatient facilities : a cross-sectional study with implications for the control of COVID-19. Lancet Glob Health. (2020) 8:780-9. doi: 10.1016/S2214-109X(20)30222-9

21. WHO. WHO Guidelines on Hand Hygiene in Health Care. Washington, DC: WHO (2009).

22. Duarte Valim M, Aparecida Pinto P, Helena Palucci Marziale M. Questionnaire on standard precaution knowledge: validation study for Brazilian nurses use. Texto Context Enferm. (2017) 26:1-8. doi: 10.1590/0104-07072017001190016

23. Gershon RRM, Vlahov D, Felknor SA, Vesley D, Johnson PC, Delcios GL, et al. Compliance with universal precautions among health care workers at three regional hospitals. Am J Infect Control. (1995) 23:22536. doi: 10.1016/0196-6553(95)90067-5

24. FMOH. Infection Prevention Guideline for Healthcare Facilities in Ethiopia. Ethiopia: Addis Ababa (2004).

25. Saqlain M, Munir MM, Rehman SU, Gulzar A, Naz S, Ahmed Z, et al. Knowledge, attitude, practice and perceived barriers among healthcare workers regarding COVID-19: a cross-sectional survey from Pakistan. J Hosp Infect. (2020) 105:419-23. doi: 10.1016/j.jhin.2020. 05.007

26. Sikakulya FK, Ssebuufu R, Mambo SB, Pius T, Kabanyoro A, Kamahoro E, et al. Use of face masks to limit the spread of the COVID-19 among western Ugandans: Knowledge, attitude and practices. PLoS ONE. (2021) 16:e248706. doi: 10.1371/journal.pone.0248706
27. Zhong B-L, Luo W, Li H-M, Zhang Q-Q, Liu X-G, Li W-T, et al. Knowledge, attitudes, and practices towards COVID-19 among Chinese residents during the rapid rise period of the COVID-19 outbreak: a quick online cross-sectional survey. Int J Biol Sci. (2020) 16:1745-52. doi: 10.7150/ijbs.45221

28. Emmanuel N. Aguwa S. Use of personal protective equipment among health workers in a Tertiary Health Institution, South East Nigeria: pre-ebola period. Int J Heal Sci Res. (2016) 6:12-8.

29. Tan W, Zhao X, Ma X, Wang W, Niu P, Xu W, et al. A novel Coronavirus genome identified in a cluster of pneumonia cases - Wuhan, China 20192020. China CDC Wkly. (2020) 2:61-2. doi: 10.46234/ccdcw2020.017

30. Erasmus V, Daha TJ, Brug H, Richardus JH, Behrendt MD, Vos MC, et al. Systematic review of studies on compliance with hand hygiene guidelines in hospital care. Infect Control Hosp Epidemiol. (2010) 31:28394. doi: 10.1086/650451

31. Seo H, Sohng K, Chang SO, Chaung SK, Won JS, Choi M. Interventions to improve hand hygiene compliance in emergency departments : a systematic review. J Hosp Infect. (2019) 102:394-406. doi: 10.1016/j.jhin.2019.03.013

32. Verbeek JH, Rajamaki B, Ijaz S, Sauni R, Toomey E, Blackwood B, et al. Personal protective equipment for preventing highly infectious diseases due to exposure to contaminated body fluids in healthcare staff. Emergencias. (2021) 33:59-61. doi: 10.1002/14651858.CD011621.pub4

33. Savoia E, Argentini G, Gori D, Neri E. Piltch-loeb R, Fantini P. Factors associated with access and use of PPE during COVID-19 : a cross-sectional study of Italian physicians. PLoS ONE. (2020) 15:e239024. doi: 10.1371/journal.pone.0239024

34. Asemahagn MA. Factors determining the knowledge and prevention practice of healthcare workers towards COVID-19 in Amhara region, Ethiopia : a cross-sectional survey. Trop Med Health. (2020) 48:111. doi: 10.1186/s41182-020-00254-3

35. Tekalegn Y, Sahiledengle B, Bekele T, Tesemma A, Aseffa T, Teferu Engida $\mathrm{Z}$, et al. Correct use of facemask among health professionals in the context of Coronavirus Disease (COVID-19). Risk Manag Healthc Policy. (2020) 13:3013-9. doi: 10.2147/RMHP.S286217

36. Hakim SA. Abouelezz and El Okda EM. Use of personal protective devices among health care workers in a teaching Hospital in Cairo, Egypt. Egypt J Occup Med. (2016) 40:287-300. doi: 10.21608/ejom.2016.846

37. Verbeek JH, Ijaz S, Mischke C, Ruotsalainen JH, Mäkelä E, Neuvonen K, et al. Personal protective equipment for preventing highly infectious diseases due to exposure to contaminated body fluids in healthcare staff (Review). Cochrane Libr. (2016) (4):1-75. doi: 10.1002/14651858.CD011621.pub2

38. Deressa W, Worku A, Abebe W, Gizaw M. Risk perceptions and preventive practices of COVID-19 among healthcare professionals in public hospitals in Addis Ababa, Ethiopia. PLoS ONE. (2021) 16:117. doi: 10.1371 /journal.pone.0242471

Conflict of Interest: The authors declare that the research was conducted in the absence of any commercial or financial relationships that could be construed as a potential conflict of interest.

Publisher's Note: All claims expressed in this article are solely those of the authors and do not necessarily represent those of their affiliated organizations, or those of the publisher, the editors and the reviewers. Any product that may be evaluated in this article, or claim that may be made by its manufacturer, is not guaranteed or endorsed by the publisher.

Copyright (c) 2021 Keleb, Ademas, Lingerew, Sisay, Berihun and Adane. This is an open-access article distributed under the terms of the Creative Commons Attribution License (CC BY). The use, distribution or reproduction in other forums is permitted, provided the original author(s) and the copyright owner(s) are credited and that the original publication in this journal is cited, in accordance with accepted academic practice. No use, distribution or reproduction is permitted which does not comply with these terms. 